\title{
A EQUIDADE DE GÊNERO NOS SERVIÇOS EM UM SETOR DE SUPERMERCADO DE ARACAJU
}

\author{
GENDER EQUITY ON THE SERVICES SECTOR IN A SUPERMARKET \\ ARACAJU
}

\author{
Maria Helena Santana Cruz ${ }^{1}$ \\ Flávio G. Bento da Silva Araújo²
}

\section{RESUMO}

A pesquisa analisa a expressão da divisão sexual do trabalho em um hipermercado Super Varejo em Aracaju (SE), destacando as especificidades introduzidas com as inovações tecnológicas e organizacionais, particularmente no setor de operadoras(es) de caixa, com o objetivo de desvelar dimensões do processo de trabalho e a construção das diferenças. Foi utilizada a abordagem qualitativa por meio do estudo de caso organizacional, a fim de apreender a dinâmica vivida no âmbito produtivo e reprodutivo. O campo empírico da pesquisa foi o hipermercado Super Varejo, especificamente no setor de frente de loja, composto pelas operadoras de caixa, embaladores, líderes de atendimento e gerentes. Os resultados informam que as imagens de gênero estruturam o processo de gestão/organização do trabalho, as políticas de seleção, treinamento, qualificação, a segmentação dos postos e a divisão sexual dos papéis. Os/as operadoras(es) mobilizam as qualificações 'tácitas' e 'sociais' circunscritas aos limites entre as lógicas da produtividade e de atendimento ao cliente. A construção das trajetórias profissionais é estruturada por estereótipos de papéis masculinos e femininos e refletem expectativas culturalmente estabelecidas. Emerge a necessidade de políticas de equidade de gênero com o objetivo de contribuir para a eliminação de todas as formas de discriminação contra mulheres no ambiente de trabalho.

Palavras-chave: Imagens de Gênero - Operadoras de Caixa - Relações de Gênero - Trabalho.

\section{ABSTRACT}

This research analyzes expression of gender division of labor in a hypermarket Super Varejo in Aracaju / SE, highlighting the specificities introduced with the technological and organizational innovations, especially in sector operators (male and female) and cashiers, with the objective of revealing dimensions of process work and construction of differences. We used a qualitative approach through case study organization, in order to grasp the dynamics experienced within productive and reproductive. The empirical field of research was the hypermarket Super Varejo, specifically in the area of store front, made by 
cashiers, packers, service leaders and managers. Those results tell that images of gender structured process management / organization of work, selection policies, training, qualification, segmentation of posts and gender division of roles. Operators (male and female) and mobilize the skills 'tacit' and 'social' circumscribed limits between the logic of productivity and customer service. The construction of professional trajectories is structured by stereotypes of male and female roles and expectations reflect culturally established. The analysis of results the research indicate that there is a need for gender equity policies in order to contribute to the removal all forms of discrimination against women in workplace.

Keywords: Images of Gender - Checkout Operators - Gender Relations Work.

\section{INTRODUÇÃO}

Nas últimas décadas, as mudanças e continuidades ocorridas no mundo do trabalho ensejaram inúmeras discussões e reavaliações das teorias e quadros analíticos da sociologia do trabalho, (re)colocando em revisão o debate sobre o trabalho, sua crise, sua centralidade na determinação da identidade e sociabilidade dos sujeitos sociais.

Com base na trajetória recente de estudos no âmbito de uma socioeconomia do trabalho, não seria descabido dizer que, nos 30 últimos anos, tem sido persistente o interesse por esse campo no Brasil, abarcando tanto a Sociologia quanto a Economia do Trabalho. No caso da Sociologia, foram os estudos feministas que, notadamente a partir do final dos anos 1960, puseram sobre a mesa a pertinência do tema da equidade entre homens $e$ mulheres no âmbito do trabalho (SAFFIOTI, 1969), desencadeando, então, um longo movimento de produção de conhecimentos. De início, ele esteve ancorado nas análises sobre as formas de acesso ao mercado de trabalho e suas consequências, mas logo se voltaram para o cotidiano dos processos de trabalho, ali observando as distintas maneiras de incluir homens e mulheres, de utilizar suas qualidades e qualificações e de lograr o consentimento de uns e de outras. Bem assim, retomaram-se os elos entre trabalho e família, produção e reprodução social. A abordagem aqui desenvolvida propõe a utilização de gênero como uma ferramenta analítica de grande relevância dada a sua 'natureza ontológica' enquanto relação social que permite 'captar a fluidez de 
certos fenômenos' e instituições sociais como os processos de socialização, a linguagem, a cultura ou, ainda, como nos interessa neste momento, o universo do trabalho.

No contexto do processo de modernização em curso no setor do hipermercado Super Varejo, a pesquisa analisa as imagens de gênero, a divisão sexual do trabalho, as relações de poder, as oportunidades de qualificação, as estratégias utilizadas pelas operadoras de caixa, na articulação do trabalho produtivo e reprodutivo. Vale ressaltar que a pesquisa se insere no horizonte de outras pesquisas realizadas no país e no exterior, preocupadas com a "imperativa reflexão sobre a especificidade da grande distribuição"3, no contexto do setor de serviços (ORBAN, 2005).

No mundo produtivo contemporâneo, um dos setores que mais absorve a força de trabalho feminina é o setor de serviços, delineando a feminização do mercado de trabalho, a qual veio acompanhada pela reestruturação produtiva e pela modernização tecnológica, e reformulou paradigmas industriais, desencadeando inúmeras transformações e impactos sobre os trabalhadores. Neste contexto, a gestão e a organização do trabalho executado pelas(os) operadores(as) de caixa são reguladas por princípios tayloristas - fragmentação e controle do trabalho -, justapostas à flexibilidade das relações e dos contratos de trabalho, que utilizam e reforçam a divisão sexual do trabalho. Autores nacionais e internacionais ${ }^{4}$ que abordam a divisão social e sexual do trabalho em grandes empresas, assim como a literatura existente sobre gênero e reestruturação produtiva indicam que, entre os setores, empresas e atividades empregadoras de homens e os que empregam mulheres, não se constrói da mesma maneira o conjunto das descontinuidades ou rupturas que marcam os novos modelos produtivos.

\subsection{O Campo de Pesquisa: O Lócus de Investigação}

O trabalho de campo foi empreendido entre outubro a dezembro de 2010 e janeiro e fevereiro de 2012, em Aracaju (SE), cidade mais populosa do Estado de Sergipe, com um total de 498.619 pessoas. A população de Sergipe integra 1.967.791 habitantes. O campo empírico da pesquisa teve como unidade de análise uma rede de hipermercado Super Varejo, anteriormente 
caracterizada por uma administração familiar, priorizando-se uma loja-piloto de um shopping, com ritmo, intensidade e representatividade diferenciados no cenário varejista estadual. A escolha da organização deveu-se ao fato de ser o principal hipermercado (loja-piloto) da rede supermercadista no Estado, e vem implementando variados procedimentos de gestão e organização do trabalho, com vista à sua modernização (inovação tecnológica, contratos em tempo parcial, mudanças na gestão). A organização adota escalas de horário, quadro variado de funções e hierarquias (gerente geral, de setor de frente de loja, encarregado, líderes de atendimento), e apresenta elevado número de funcionários(as) no setor de operação de caixas, com a presença de operadoras part-time (tempo parcial). O setor de frente possui 44 checkouts (caixas eletrônicos), com terminais PDV (ponto de venda) com leitora ótica, esteiras e sensores com fotocélulas e balanças; dispõe de 220 funcionários, entre os quais 135 operadoras(es) de caixa - 126 mulheres e 9 homens ${ }^{5}$. As caixas eletrônicas são organizadas em duas seções abrangendo caixas de pequenas compras e caixas de grandes compras.

\subsection{Percurso Metodológico}

As especificidades do objeto, objetivos e aspectos metodológicos recaíram sobre a pesquisa qualitativa, pela compreensão de que a mesma se aprofunda no mundo dos significados das ações e relações humanas. Quanto aos meios empregados, a pesquisa é estudo de caso organizacional, a fim de possibilitar compreender as especificidades das relações de trabalho em nível macro, e estabelecer conexões de análises em nível micro. Os estudos de caso apontam singularidades setoriais e/ou regionais num contexto histórico caracterizado por profundas mudanças nas relações de trabalho e contribuem para revelar a existência de situações, que aproveitam as diferenças sociais entre os trabalhadores, construídas 'fora da produção e preexistentes' à inserção econômica dos indivíduos.

Os procedimentos para a coleta de dados foram concebidos "como um caminho para melhor se apreender o real" (JACOBINI, 2003). Foram consultadas várias fontes de informação: a revisão da literatura pertinente ao objeto da pesquisa; documentos sobre a história da organização; estatísticas 
sobre a população de operadoras de caixa (sexo, idade, estado civil, escolaridade, número e idade dos filhos, horário de trabalho e tempo de serviço), estatísticas de institutos de pesquisa (IBGE, DIEESE, MTE, Secretaria de Planejamento de Sergipe), com o objetivo de traçar o perfil dos trabalhadores do setor de comércio varejista; foram ainda obtidas estatísticas sobre o mercado de trabalho, para a apreensão das dimensões estruturais, contribuindo para a apropriação do objeto e a construção do conhecimento, estabelecendo-se relações no contexto nacional e estadual do mercado de trabalho (CRUZ, 2005).

A observação direta ou observação em campo foi realizada no espaço em que as operadoras de caixa desenvolvem o seu trabalho, que é a área de circulação dos clientes da organização; a escolha desse local teve como finalidade propiciar uma análise da natureza do trabalho realizado no quotidiano das trabalhadoras, para captar a diversidade de sinais de subordinações e de resistências (CRUZ, 2002), levando em consideração os efeitos das ações tanto imediatas quanto institucionalizadas (MINAYO, 1999). A entrevista semiestruturada foi realizada com um conjunto de respondentes: um gerente do departamento de recursos humanos (25 anos na empresa), um gerente geral administrativo (29 anos na empresa), um gerente de setor do frente de loja (nove anos de empresa) e 19 funcionárias(os) do setor de frente de loja, sendo 18 operadoras(es) e uma embaladora - selecionada em razão de trabalhar como operadora de caixa quando necessário, e ter concluído, durante o período pesquisado, um curso técnico profissionalizante. Foi privilegiado o setor de frente de loja, por integrar operadoras de caixa, embaladores, líderes de atendimento e gerentes.

O processo de análise de conteúdo com base na hermenêuticadialética mostrou-se relevante para se identificarem as convergências/ /divergências nas mensagens obtidas com as/os respondentes, com base nos temas abordados, permitindo a inferência de conhecimentos relativos às condições de produção/recepção destas mensagens (BARDIN, 1991). 


\section{ABORDAGEM TEÓRICA}

Coerente com uma perspectiva ontológica de crítica des/construcionista do conhecimento e de defesa da dimensão relacional dos objetos no campo das Ciências Sociais, acreditamos que, no caso dos estudos sobre gênero e trabalho, o primeiro desafio é romper com qualquer tentação de tratar este objeto (tão conhecido de todos nós) de forma naturalizada e ideologizada pelos padrões historicamente estabelecidos. Tal preocupação fundamenta-se na necessidade de deixar clara a adesão a uma epistemologia feminista - que realiza uma crítica des/construcionista da teoria social e tem um olhar "assumidamente" situado num "ponto de vista"- e a uma "ontologia relacional" (HARAWAY, 1995). O que significa trabalhar com gênero como uma categoria política, enquanto relações de poder - logicamente que articulada a outras dimensões como classe, raça/etnia e idade/geração (SAFFIOTI, 2000).

A abordagem das relações sociais de gênero fundamenta-se na compreensão de que as distinções entre trabalhadores(as) resultam de construções culturais, isto é, são produtos da cultura e não decorrentes de dados biológicos. O gênero como conceito central apresenta dimensões de análise histórica, cultural e política, de caráter relacional, transversal para as ciências sociais. Segundo Scott (1989), o gênero implica quatro elementos relacionados entre si: 1) símbolos culturalmente disponíveis que evocam representações múltiplas; 2) conceitos normativos que colocam em evidência interpretações do sentido dos símbolos que tentam limitar e conter as suas possibilidades metafóricas; 3) as relações de poder e dominação presentes nas instituições e organizações sociais; 4) a identidade subjetiva. As relações de poder e dominação constituem e são constituídas pelos discursos e representações sociais, imersos nos valores da cultura atual, na institucionalização de normas sancionadas pela coletividade, nas regras de comportamentos, nos estilos de comunicação, no sistema informal de relacionamentos identificados e fundados nas experiências dos homens, vinculadas por relações hierárquicas de poder desfavoráveis ao gênero feminino.

Para Foucault, as relações de poder enraízam-se no conjunto da rede social. Isto não quer dizer que há um princípio de Poder primeiro e 
fundamental que domina até o menor elemento da sociedade; mas sim que, a partir da possibilidade de ação sobre a ação dos outros - que é coextensiva a toda a relação social -, de formas múltiplas de disparidade individual, de objetivos, de instrumentações dadas sobre nós e os outros, de institucionalização - mais ou menos setorial ou global -, de organização - mais ou menos refletida -, definem-se as formas diferentes de poder (FOUCAULT, 1984, p.13).

O trabalho entendido como 'suporte privilegiado de inscrição da estrutura social', é um dos mecanismos sociais que insere os sujeitos numa moldura de sociabilidade, possibilitando o reconhecimento de si; é uma categoria central na formação das identidades diferenciadas de homens e mulheres (CRUZ; CRUZ 2008). Nesse processo, as identidades - múltiplas e plurais - de mulheres e homens vão se construindo no interior de relações e práticas sociais, que constituem e instituem os sujeitos e produzem as formas como as instituições sociais são organizadas e percebidas.

A movimentação da mulher para a esfera pública do trabalho é parte integrante do processo de democratização da vida social, permite abranger a ampliação da cidadania e dos direitos das(os) trabalhadoras(es). O crescimento da participação feminina no mercado de trabalho brasileiro foi uma das mais importantes transformações sociais ocorridas no país a partir da década de 1970; a partir daí, ampliou-se de forma acentuada e diversificada, desde $1985-1995$, passando de $37 \%$ para $53 \%$, enquanto a masculina passou de $76 \%$ para $78 \%$, com menor alteração, sobretudo no mercado de trabalho urbano, e não mostra nenhuma tendência a retroceder, apesar das sucessivas crises econômicas que têm assolado o país a partir dos anos 1980 (OIT, 2007).

Em 1999, no Brasil, $11,67 \%$ das mulheres empregadas no setor formal da economia estavam concentradas em apenas oito tipos de ocupações: professoras, funcionárias públicas, empregadas em funções administrativas, vendedoras, cozinheiras, empregadas em conservação e limpeza de edifícios, empregadas em serviços pessoais e de enfermagem e costureiras. Ao leque restrito de profissões encontradas e à inserção diferenciada de homens e mulheres no mercado de trabalho em setores profissionais e de carreiras denomina-se segmentação horizontal e vertical baseada no gênero, comportando níveis diferenciados/assimétricos de poder técnico e decisório. A 
segmentação reporta-se à concentração de oportunidades de trabalho para as mulheres em setores específicos dentro da estrutura produtiva, engendrando baixa remuneração das ocupações tipicamente femininas, especialmente no setor de serviços (discriminação encoberta) bem como dificuldade para estabelecer o valor de seu trabalho (autodiscriminação).

A noção moderna de trabalho como foi formalizada pela economia política clássica, conforme Hirata \& Zarifian (2003), remete a uma dupla definição. A primeira apresenta-se como uma definição antropológica, o trabalho constituindo uma característica geral e genérica da ação humana. $O$ desenvolvimento histórico do conceito de trabalho foi formalmente interpelado nos anos 1970 com o avanço das pesquisas que introduziram a dimensão sexuada nas análises do trabalho conforme assinalado por Hirata (1998). É a partir da problemática da divisão sexual do trabalho que Kergoat procede a uma desconstrução/reconstrução do conceito de trabalho e seus conceitos conexos, como o de qualificação, introduzindo a dimensão do trabalho doméstico e a esfera da reprodução junto com outras que atuam no mesmo campo (no $\mathrm{CNRS}^{6}$, na Universidade, mas também fora das instituições). Assim, algumas pesquisadoras do GEDISST $^{7}$, como D. Kergoat, propuseram uma reconceituação do trabalho, por inclusão: 1) do sexo social e 2) do trabalho doméstico, no conceito de trabalho. Essa reconceituação abrangeu também o trabalho não-assalariado, não remunerado, não mercantil e informal. Trabalho profissional e trabalho doméstico, produção e reprodução, assalariamento e família, classe social e sexo social são considerados categorias indissociáveis.

Considerou-se necessário articular o prisma das relações sociais de sexo e da divisão sexual do trabalho (separação da esfera dos afazeres privado/ /doméstico/gratuito/feminino da esfera do trabalho público/produtivo/remunerado/ /masculino) com a construção da cidadania, para evidenciar algumas das mais importantes ambiguidades e impasses da formação teórica da cidadania na sociedade contemporânea, principalmente quando se trata da análise do mundo do trabalho. A divisão do trabalho entre os sexos é um marco analítico na pesquisa que permite superar as disjunções conceituais (homem/mulher, trabalho/não trabalho, trabalho assalariado/trabalho doméstico) utilizadas pela análise econômica e pela sociologia do trabalho, permitindo uma ampliação do conceito de trabalho 
compreendido como atividade profissional e atividade desenvolvida na esfera doméstica (HIRATA; KERGOAT, 2008). A divisão sexual do trabalho é um conceito pertinente para pensar as relações no trabalho, as quais são um aspecto das relações sociais entre homens e mulheres, e, embora seja um dos muitos lócus das relações de gênero, não esgota a problemática dessas relações, na medida em que elas comportam construções culturais e históricas, interdependentes e complementares (SOUZA-LOBO, 1991).

A relação de trabalho como relação social traz embutida uma relação de poder entre os sexos. A dinâmica das relações de poder estrutura as imagens de gênero que são representações sobre as identidades masculina e feminina, produzidas social e culturalmente, e que condicionam fortemente as formas diferenciadas de oportunidades de inserção de homens e mulheres no mundo do trabalho. Elas são elementos fundamentais na constituição de uma ordem de gênero e de uma divisão sexual do trabalho,

[...] as imagens são prévias à inserção de homens e mulheres no trabalho, sendo produzidas e reproduzidas desde as etapas iniciais de socialização dos indivíduos, estão baseadas na separação entre o privado e o público, o mundo familiar e o mundo produtivo, e na definição de uns como territórios de mulheres e outros como territórios de homens (ABRAMO, 2007, p. 5).

Conforme Hirata e Kergoat (2008), um dos princípios que vai organizar a divisão social, segundo o sexo do trabalhador, é a existência de trabalhos de homens e trabalhos de mulheres. Por isso mesmo, a definição de qualificações, de carreiras, de promoções não só é diferente para homens e mulheres, mas remete, em cada situação concreta, às relações de força (SOUZA-LOBO, 1991). A própria categoria divisão do trabalho passa a ser pensada como mais que simples divisão de tarefas, implicando uma diferenciação de funções com distribuição assimétrica do controle, da hierarquia, da qualificação, da carreira e do salário. A "divisão sexual do trabalho" é uma categoria utilizada pelas Ciências Sociais para indicar que, em todas as sociedades, homens e mulheres realizam tarefas distintas. Sem dúvida, as tarefas atribuídas a cada sexo variam de cultura para cultura. Existe consenso de que o debate sobre divisão sexual do trabalho deveria passar pelo 
debate sobre outras divisões, como por exemplo a do poder e as suas articulações na delimitação de gênero, em distintos espaços.

\section{ALGUNS RESULTADOS}

De acordo com o Ministério do Trabalho e Emprego - MTE (BRASIL, 2010), em abril de 2010 o setor de Comércio apresentou desempenho recorde, com a geração de 40.725 postos de trabalho (+0,55\%), resultante de aumentos recordes nos seus dois ramos: comércio varejista (+34.015 postos) e comércio atacadista (+6.710 postos de trabalho). Balanço realizado em 2010 pelo DIEESE informa a composição da força de trabalho: homens (55\%), comparativamente a $45 \%$ mulheres entre os trabalhadores formais (DIEESE; CESIT, 2005). Na maioria dos supermercados, os homens são contratados como repositores - função que exige força física para movimentar algumas mercadorias - e ocupam as chefias do setor; as mulheres são contratadas para vagas de atendimento ao público, nas funções de embaladoras, atendentes e operadoras de caixas (PAULINO et al., 2005). As mulheres representam 94\% dos funcionários no setor de frente dos supermercados, enquanto as operadoras de caixa representam 84\%, confirmando a tendência da segregação feminina (DIEESE, CESIT, 2005; KAUFMANN, 2001; CRUZ, S., 2003). No setor de operação de caixa do hipermercado S. Varejo ${ }^{8}$ consta 0 total de 135 funcionários, sendo 126 do sexo feminino e 09 do sexo masculino.

Com relação à escolaridade ${ }^{9}$, o ensino médio completo é o requisito exigido para admissão no cargo de operador(a) de caixa, embalador(a) e repositor. Além do ensino médio completo, a maioria das mulheres possuía cursos de informática, cursos de recepcionista, telefonista e outros direcionados para o setor de serviços (frentista, atendente). Algumas iniciaram o curso pré-vestibular, mas desistiram em virtude do horário de saída do trabalho. Em relação à idade, as entrevistadas encontram-se na faixa etária de 26 a 30 anos, diferindo um pouco da média verificada em outros estados, no setor de supermercados, em que a proporção de homens e mulheres é maior entre 18 e 24 anos, conforme dados do DIEESE (2010). A idade constitui um dos atributos de gênero, uma variável individual imbuída de sentido econômico, cultural e ideológico (CRUZ, 2005). A absorção das trabalhadoras em 
diferentes setores da atividade econômica é influenciada por atributos de gênero como: idade, estado civil, número e idade dos filhos, projetos individuais e familiares e conciliação com as atividades realizadas no âmbito privado (CRUZ, 2005).

Quanto ao estado civil, a totalidade das operadoras de caixa do setor de frente é solteira. As mulheres casadas correspondem ao maior percentual de funcionários(as) com filhos (um a quatro filhos). Para Bruschini, Ricoldi e Mercado (2008), a presença de filhos pequenos é um fator que dificulta sobremaneira a atividade produtiva feminina, na medida em que 0 cuidado com os filhos é uma das atividades que mais consome o tempo do trabalho doméstico das mulheres.

Um dos impactos das transformações tecnológicas para as operadoras de caixa é a intensificação do trabalho causada pelo aumento de funções a serem exercidas, com a informatização dos checkouts (caixas), banalizando e simplificando as tarefas, e produzindo um aumento do ritmo de trabalho (KAUFMANN, 2001). O setor de serviços é caracterizado frequentemente pela atribuição de tarefas monótonas, repetitivas, estressantes, um trabalho part-time (JOFFER, 2008; HIRATA e KERGOAT, 1991). As operadoras de caixa iniciam o ingresso ao trabalho como fixa ou part-time (tempo parcial); é um trabalho caracterizado pela intersecção das demandas de produtividade, pela gestão dos clientes, um lugar de intersecção de relações de classe, de sexo e de etnia, é o ponto de acesso (gateway) (GIDDENS, 1991) entre os clientes e o supermercado.

As operadoras são as pessoas-chave para o padrão de qualidade no atendimento, representam a imagem institucional da empresa, que apreende os estereótipos sexistas atribuídos à mulher, relativos à sua capacidade para atender aos clientes, ser gentil e atenciosa, maximizando a eficiência dos serviços. Em um trabalho masculino, a diplomacia ainda é reconhecida como uma qualificação importante, mas em um trabalho tradicionalmente feminino, como o trabalho de caixa, a diplomacia não é considerada como uma qualificação, como um ato de gentileza, delicadeza e paciência, características atribuídas à "natureza feminina" (SOARES, 1997, pp. 110-111).

Nas grandes lojas do terciário - no comércio varejista de supermercados e hipermercados -, segmento no qual se realiza o último 
estágio de circulação de mercadorias para o consumo (FRANÇA JÚNIOR, 2007), com grandes estoques de empregos e introdução das inovações tecnológicas e organizacionais, as qualificações tácitas femininas são elementos fundamentais na melhoria da qualidade e produtividade. As qualificações tácitas femininas (KERGOAT, 1986), formadas pela "totalidade do trabalho reprodutivo", podem ser denegadas pelos empregadores, não são reconhecidas como qualificações profissionais (HIRATA, 1995), visto que essas qualidades são julgadas como devendo ser inatas e não adquiridas, são inerentes à natureza e não provenientes da cultura (KERGOAT, 1986; SOUZA-LOBO, 1991).

Os conhecimentos adquiridos por trabalhadoras e trabalhadores através dos processos e instituições sociais, somados às suas habilidades adquiridas socialmente e suas características pessoais, constituem um conjunto de saberes e habilidades que significam, para as mulheres, valor de uso e que no ambiente de trabalho, podem ser transformados em valor de troca, se de fato for reconhecido (CRUZ, 2005). As qualidades atribuídas à mão de obra feminina, aquilo que é definido como qualidade natural intrínseca à natureza das mulheres é, em realidade, o produto da educação, de processos de socialização das meninas no trabalho doméstico, sendo formadas para efetuarem tarefas - não remuneradas e não valorizadas - monótonas, repetitivas, com minúcia, rapidez, destreza e habilidade manual (SOUZALOBO, 1991).

Os empregos existentes em certas atividades de serviço, com forte presença feminina, se baseiam na naturalização das "qualidades femininas" como a paciência, destreza etc. (ZARIFIAN, 2008). Conforme Kergoat (2009), as mulheres têm práticas e competências que não são reconhecidas como tais - aquelas que se desenvolvem continuamente na esfera doméstica - e que podem ser reconvertidas para o trabalho produtivo, ou, nesse caso específico, para funções no setor de serviços. Nas áreas de reposição, onde é exigida força física para movimentar algumas mercadorias, a maioria dos trabalhadores é do sexo masculino.

$\mathrm{Na}$ análise da qualificação das operadoras de caixa, foram considerados os aspectos: cognitivos, o 'saber fazer' no trabalho que as mulheres desenvolvem (a escolaridade e treinamento); os aspectos da 
personalidade e comportamentais, relativos ao 'saber ser', as chamadas qualificações tácitas que remetem a três dimensões: processo de aprendizagem, resultado da prática de tarefas rotineiras adquiridas através da experiência; a existência de diferentes níveis de consciência tomados de acordo com a atividade a ser realizada; e a natureza coletiva do processo de trabalho, favorecendo o desenvolvimento de subjetividades e identidades (JONES; WOOD, 1984).

Segundo Hirata (2002), no setor terciário, a automação cria empregos não-qualificados que ao se tornarem feminilizados, acabam fazendo da não-qualificação uma espécie de qualificação "tipicamente" feminina. A diplomacia é um exemplo de qualificação tácita "invisível" de grande importância, nas interações que as operadoras de caixa realizam com a clientela, para evitar constrangimento (situações embaraçosas) para os outros ou a si mesmas no atendimento ao público. As operadoras ressaltam as habilidades básicas para o trabalho:

Tem que ter primeiramente muita paciência, saber lidar com cada cliente, porque cada um deles é diferente um do outro [...]; aí tem que ter simpatia, paciência, vamos ver juntos, muitas vezes eu vou até na seção para pegar, para mostrar para ela, então a gente acaba, assim, conversando". (Operadora).

Ao reduzir as práticas sociais a papéis sociais sexuados (KERGOAT, 2009), essas habilidades adquiridas - qualificações tácitas e sociais - são desqualificadas e desvalorizadas, preservando, assim, a hierarquia dos poderes e dos papéis, as assimetrias de gênero no trabalho reprodutivo e produtivo.

As operadoras de caixa enfrentam pressões que não se restringem ao âmbito profissional, resultam também do esforço/conflito da dupla jornada para a conciliação entre as atividades remuneradas e as domésticas, realizadas de modo gratuito para toda a família. Elas, em geral, colocam os filhos pequenos em creches para se dedicar ao trabalho remunerado, garantindo o sustento de sua família. A sobrecarga com dupla jornada de trabalho é observada em todas as classes sociais, constitui um dos fatores que permite falar em superexploração do trabalho feminino.

O número de horas gastas com os afazeres domésticos no Brasil vem diminuindo com a aquisição de eletrodomésticos pelas famílias e a ajuda 
de empregadas domésticas que poupam tempo de trabalho das mulheres em casa. Na população com menos de quatro anos de estudo, por exemplo, a proporção de homens que cuidam de afazeres domésticos é de $47 \%$, ante $89 \%$ das mulheres. Entre os mais escolarizados, o percentual masculino aumenta e chega a 54\%, mas a das mulheres não muda praticamente nada: 88,7\% (IBGE, 2010).

\section{CONSIDERAÇÕES FINAIS}

As imagens de gênero dos gestores, orientadas pela ideologia da masculinidade e feminilidade, continuam a organizar a divisão sexual do trabalho, as diferenças nas ocupações masculinas ou femininas, sexualizando socialmente os postos de trabalho. O trabalho das operadoras de caixa é caracterizado por uma forte disciplina e controle rígido do seu tempo no trabalho, do seu corpo, do seu comportamento e suas emoções.

As/os trabalhadores do setor de frente de loja recebem como remuneração o salário básico, a média do valor de um salário mínimo. A rotatividade como estratégia de redução de salários fortalece a precarização dos postos de trabalho. Com frequência, as trabalhadoras utilizam estratégias (absenteísmo, solidariedade, pausas não autorizadas, etc.) para atenuar os efeitos das relações de poder do taylorismo e da gestão flexível sobre o trabalho.

No setor varejista de supermercado e hipermercado, o trabalho realizado por homens e mulheres constitui um lócus importante de reprodução das imagens de gênero, principalmente no setor de frente de loja, no qual as operadoras de caixa estão inseridas, e onde existe uma presença significativa de mulheres trabalhando. Por ser um setor em constante processo de modernização, marcado por significativas transformações na organização e gestão do trabalho, devido à introdução das novas tecnologias, as imagens de gênero no trabalho são constantemente reproduzidas, passam a ser um elemento estruturante da divisão sexual do trabalho e da segmentação ocupacional desse setor e podem se constituir em um obstáculo à equidade de gênero no trabalho. 


\section{REFERÊNCIAS}

ABRAMO, L. A inserção da mulher no mercado de trabalho: uma força de trabalho secundária? Tese (Doutorado em Sociologia) 327 p. Departamento de Sociologia, Faculdade de Filosofia, Letras e Ciências Humanas, Universidade de São Paulo, São Paulo, 2007.

ABREU, Alice Rangel de Paiva. Especialização flexível e gêneros, debates atuais. XVII Encontro Anual da ANPOCS, 22 a 25 de outubro de 1993, Caxambu (MG), 1993.

BARDIN, Laurence. Análise de conteúdo. Lisboa, Portugal: Edições 70, 1991.

BRASIL. Ministério do Trabalho e Emprego. Cadastro Geral de Empregados e Desempregados - CAGED. [Documento eletrônico] Disponível em: $<$ https://granulito.mte.gov.br/ portalcaged/paginas/home/home.xhtml> Acesso em abr. 2010.

BRUSCHINI, Cristina; RICOLDI, A. M.; MERCADO, C. M. Trabalho e gênero no Brasil até 2005: uma comparação regional. In: BRUSCHINI, C., et al (org.). Mercado de trabalho e gênero: comparações internacionais. Rio de Janeiro: FGV, 2008.

CRUZ, Maria Helena Santana. Inovações tecnológicas e relações de gênero no setor de serviços financeiros bancários. Revista do Mestrado em Educação, UFS, v. 4, p. 131-144, já./jun., 2002.

.Trabalho, gênero, cidadania: tradição e modernidade. São Cristóvão: Editora UFS; Aracaju: Fundação Oviêdo Teixeira, 2005.

CRUZ, Maria Helena Santana ; CRUZ, Karina S. Introduzindo a abordagem de gênero no trabalho em saúde pública. In: CRUZ, Maria H. S. (org.). Pluralidade de saberes e territórios de pesquisa em educação sob múltiplos olhares dos sujeitos investigadores. São Cristóvão: Editora UFS, 2008.

CRUZ, Sofia Alexandra. Entre a casa e a caixa. Retrato de trabalhadoras na grande distribuição. Porto: Edições Afrontamento, 2003.

DEPARTAMENTO INTERSINDICAL DE ESTATÍSTICAS E ESTUDOS SOCIOECONÔMICOS - DIEESE. CENTRO DE ESTUDOS SINDICAIS E DE ECONOMIA DO TRABALHO - CESIT (orgs.). Trabalho e abordagem pluridisciplinar: estudos Brasil, França e Argentina. São Paulo: DIEESE; Campinas: CESIT/Unicamp, 2005.

Balanço do segmento e perfil dos trabalhadores em supermercados [Documento eletrônico] - São Paulo - Julho 2010 Disponível em: <http://dieese.org.br/esp/balançoSetorSupermercadistaemSP.pdf>. Acesso em set. 2010. (2010). 
FOUCAULT, Michel. Deux essais sur le sujet et le pouvoir. In: FREYFUS, H. e RABINOW P., Michel Foucault. Un parcours philosophique, Paris: Gallimard, 1984, pp. 297-321.

FRANÇA JÚNIOR, Luzimar Barreto. 0 trabalho na grande rede hipermercadista - um estudo sobre o Carrefour e a reestruturação na década neoliberal. (2007) [Documento eletrônico] Disponível em $<w w w . e s t u d o s d o t r a b a l h o . o r g / a n a i s$ 6seminario dotrabalho/luzimar barretofrancajunior.pdf > Acesso em mar. 2010.

GIDDENS, Anthony. As conseqüências da modernidade. São Paulo: UNESP, 1991.

HARAWAY, Donna. Saberes localizados: a questão da ciência para o feminismo e o privilégio da perspectiva parcial. Cadernos Pagu, v. 5, p. 07-42, 1995.

HIRATA, Helena. Nova divisão sexual do trabalho? Um olhar voltado para a empresa e a sociedade. São Paulo: Boitempo, 2002.

Divisão - relações sociais de sexo e do trabalho: contribuição à discussão sobre o conceito de trabalho. Em Aberto, Brasília, ano 15, n. 65, jan./mar. 1995.

Reestruturação produtiva, trabalho e relações de gênero. Revista Latino Americana de Estúdios do Trabalho. Gênero, Tecnologia e Trabalho. Buenos Aires, ano 4, n. 7, 1998, p. 5-28.

HIRATA, Helena; KERGOAT, D. Paradigmas sociológicos e categoria de gênero. Que renovação aporta a epistemologia do trabalho? Novos Cadernos NAEA, v. 11, n. 1, p. 39-50, jun. 2008.

HIRATA, Helena; KERGOAT, D. Força e fragilidade do modelo japonês. In: Revista Estudos Avançados, 12(5), 1991.

HIRATA, Helena; ZARIFIAN, Philipe. O Conceito de trabalho. In: MARLI, Emilio (Org). Trabalho de cidadania ativa para as mulheres. Desafios para as Políticas Públicas. São Paulo: Coordenadoria Especial da Mulher, 2003, p. 65-69.

INSTITUTO BRASILEIRO DE GEOGRAFIA E ESTATÍSTICA - IBGE. Pesquisa mensal de emprego - Mulher no mercado de trabalho: Perguntas e respostas. 08 de março de 2010 - IBGE. [Documento eletrônico] Disponível em <www.ibge.gov.br/home/estatistica/indicadores/trabalhoerendi mento/pme_nova/defaultestudos.shtm> Acesso em: 30 ago. 2011.

JACOBINI, Maria Letícia de Paiva. Metodologia do trabalho acadêmico. Campinas (SP): Alínea, 2003.

JOFFER, Suzana da Cunha. As relações de gênero no trabalho: uma análise da inserção das mulheres e homens na rede de fast food. Fazendo Gênero 8 
- Corpo, Violência e Poder. [Documento eletrônico] Florianópolis, de 25 a 28 de agosto de 2008. Disponível em: <www.fazendogenero8.ufsc.br/.../ Suzana_ da_Cunha_Joffer_29 pdf>. Acesso em abr. 2009.

JONES, Bryan; WOOD, S. Qualification tacites, division du travail et nouvelles tecnologies. Sociologie du travail. $n^{\circ}=4,1984$, p. 407-421.

KAUFMANN, Anna E. S. O trabalho flexível na empresa enxuta e suas conseqüências para as operadas de caixa em supermercados. Núcleo de Estudos da Mulher e Relações de Gênero, UEFS-DCHF, Feira de Santana/BA, 2001.

KERGOAT, Daniele. Em defesa de uma sociologia das relações sociais: Da análise crítica das categorias dominantes à elaboração de uma nova conceituação. In: KARTCHEVSKY-BULPORT, André et al. 0 sexo do trabalho. Rio de Janeiro: Paz e Terra, 1986.

KERGOAT, Daniele. Divisão sexual do trabalho e relações sociais de sexo. In: HIRATA, Helena et al. (orgs.). Dicionário crítico do feminismo. São Paulo: Editora UNESP, 2009.

MINAYO, M. C. S. O desafio do conhecimento. Pesquisa qualitativa em saúde. São Paulo/Rio de Janeiro: Hucitec-Abrasco, 1999.

ORBAN, Edouard. O Serviço é um produto? In: DIEESE (Org.). O trabalho no setor terciário: emprego e desenvolvimento tecnológico. São Paulo: DIEESE; Campinas: CESIT, 2005.

ORGANIZAÇÃO INTERNACIONAL DO TRABALHO. OIT - Relatório "Panorama da situação de trabalho de mulheres", publicado em 06 de março de 2007.

PAULINO, Ana Yara et al. Relações de trabalho e relações sindicais na empresa transnacional supermercadista Carrefour no Brasil. In: DIEESE; CESIT (org). Trabalho e abordagem pluridisciplinar: estudos Brasil, França e Argentina. São Paulo: DIEESE; Campinas: CESIT/IE/Unicamp, 2005.

SAFFIOTI, Heleieth I. B. Já se mete a colher em briga de marido e mulher. A Violência Disseminada - São Paulo em Perspectiva. Revista da Fundação SEADE, Vol. 13/nº 4, p. 82-91, 2000.

SAFFIOTI, Heleieth. A mulher na sociedade de classes: mito e realidade. São Paulo: Quatro Artes, 1969.

SCOTT, Joan. Gênero: uma categoria útil para análise histórica. Recife, SOS Corpo 1989.

SEGNINI, R. P. Mulher em tempo novo: mudanças tecnológicas nas relações de trabalho. UEC. 1995. Tese (Doutorado Livre Docência em Economia 
Política da Educação) Faculdade de Educação da Universidade Estadual de Campinas. Campinas (SP), 1995.

SERGIPE. Secretaria de Estado de Planejamento. Sergipe em dados 2008 SEPLAN. [Documento eletrônico] Disponível em: <www.seplan.se.gov.br/ modules/tinyd0/index. php? id=88> Acesso em mar. 2010.

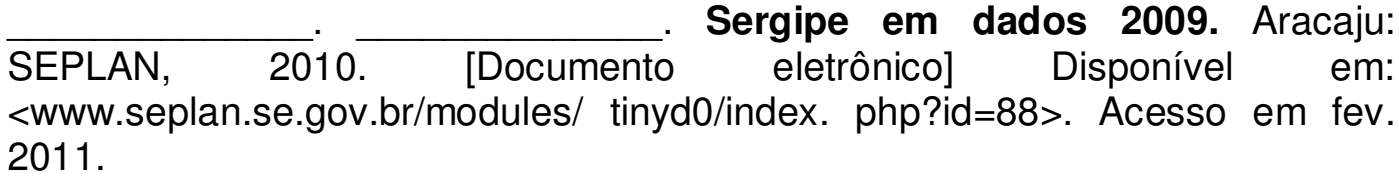

SOARES, Ângelo. Se eu pudesse não ser caixa de supermercado. Estudos Feministas, Rio de Janeiro, UFRJ, v. 5, n. 1, p. 82-102, jan/jun 1997.

SOUZA-LOBO, Elizabeth. A classe operária tem dois sexos. São Paulo: Brasiliense, 1991.

ZARIFIAN, P. Objetivo competência: por uma nova lógica. São Paulo: Atlas, 2008.

\footnotetext{
${ }^{1}$ Maria Helena Santana Cruz. Doutora e Mestre em Educação pela Universidade Federal da Bahia; Pós-doutora em Sociologia da Educação; Professora dos Programas de Pós-Graduação em Educação e Sociologia da Universidade Federal de Sergipe; Grupo de pesquisa (CNPq): "Educação, Formação, Processo de Trabalho e Relações de Gênero" (UFS); CV: http://lattes.cnpq.br/4620908024396665; Email: helenacruz@uol.com.br;

${ }^{2}$ Flávio G. Bento da Silva Araújo - Bacharel em Ciências Sociais, Especialista em Educação e Mestre em Sociologia pela UFS; Email:flaviogbe9np20-=to@yahoo.com.br

${ }^{3}$ Cf. Orban (2005) termo genérico utilizado na França para designar os supermercados, os hipermercados, as grandes redes varejistas etc.

${ }^{4}$ Saffioti, 1969; Souza-Lobo, 1991; Abreu, 1993; Segnini, 1995, Hirata, 1998, entre outros.

${ }^{5}$ Dados fornecidos pela empresa através de documentos e planilhas.

${ }^{6}$ Centre National de Recherche Scientificque. (Nota do Autor).

${ }^{7}$ Grupo de Estudos da Divisão Internacional Social e Sexual do Trabalho.

8 . Dados fornecidos pelo Departamento de RH da empresa, enviados por correio eletrônico, no formato de planilhas em outubro de 2010.

${ }^{9}$ O Departamento de Recursos Humanos da rede S.Varejo, em sua política de recrutamento para os cargos da base do setor operacional, prioriza a contratação de pessoas com perfil de primeiro emprego, sem experiência de trabalho anterior, com apenas o ensino médio concluído. A expectativa de ampliar a escolaridade entre os respondentes depende de vários mecanismos como as escalas de trabalho, os arranjos familiares, o comprometimento de sua renda com a manutenção da família e a realização de projetos pessoais e familiares.
}

RECEBIDO EM: novembro/2013

APROVADO EM: dezembro/2013 